\title{
LA-UR-19-23283
}

Approved for public release; distribution is unlimited.

Title: $\quad$ Expertise and capabilities of EES/LANL in long-term monitoring of legacy waste sites

Author(s): $\quad$ Telfeyan, Katherine Christina

Intended for: $\quad$ Presentation for DOE Legacy Management Workshop in Augusta, GA April 16-17

Issued: 
Disclaimer:

Los Alamos National Laboratory, an affirmative action/equal opportunity employer, is operated by Triad National Security, LLC for the National Nuclear Security Administration of U.S. Department of Energy under contract 89233218CNA000001. By approving this article, the publisher recognizes that the U.S. Government retains nonexclusive, royalty-free license to publish or reproduce the published form of this contribution, or to allow others to do so, for U.S. Government purposes. Los Alamos National Laboratory requests that the publisher identify this article as work performed under the auspices of the U.S. Department of Energy. Los Alamos National Laboratory strongly supports academic freedom and a researcher's right to publish; as an institution, however, the Laboratory does not endorse the viewpoint of a publication or guarantee its technical correctness. 


\section{Expertise and capabilities of EES/LANL in long-term monitoring of legacy waste sites}

Katherine Telfeyan, LANL DOE Legacy Management National Labs Engagement Workshop Augusta, Georgia April 16-17 


\section{Laboratory Capabilities}

\section{- DOE Environmental Management} Projects: $\mathrm{Cr}(\mathrm{VI})$ and RDX groundwater plumes in Los Alamos

- Natural Attenuation Studies:

- Hydrogeochemical and Sedimentological characterizations

- Stable isotope analysis $(\mathrm{O}, \mathrm{H}, \mathrm{N}, \mathrm{C})$

- Batch and column experiments with outcrop and aquifer samples show little to no natural attenuation of contaminants

- X-ray synchrotron experiments conducted to confirm $\mathrm{Cr}(\mathrm{VI})$ reduction to $\mathrm{Cr}(\mathrm{III})$

\section{- Chemical Remediation:}

- Batch and column experiments conducted with sodium dithionite and molasses to create in-situ redox barrier to immobilize $\mathrm{Cr}(\mathrm{VI})$ and $\mathrm{RDX}$

- Sodium dithionite: direct chemical reduction of sedimentary $\mathrm{Fe}$ (III) to form in-situ redox barrier

- Molasses: biostimulation of natural microbial population reduces sedimentary $\mathrm{Fe}$ (III)

- Microcosms characterized
Natural

attenuation studies indicate aquifer

sediments offer no attenuation of RDX (Heerspink et al., 2017)
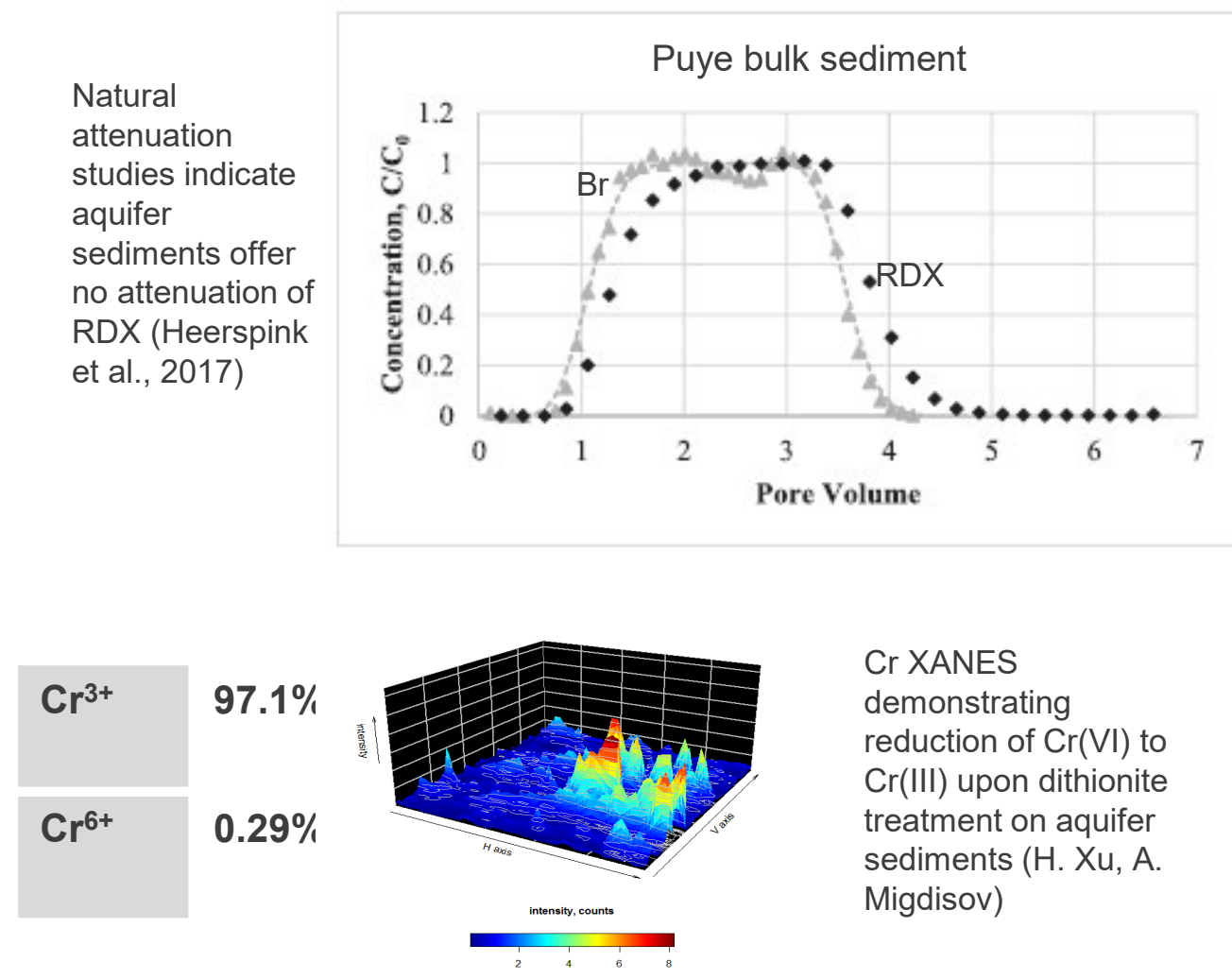

Cr XANES

demonstrating

reduction of $\mathrm{Cr}(\mathrm{VI})$ to $\mathrm{Cr}$ (III) upon dithionite treatment on aquifer sediments $(\mathrm{H}$. Xu, A. Migdisov)

\section{Column}

breakthroughs of

$\mathrm{Cr}(\mathrm{VI})$ after sediment

treated with sodium dithionite: treated sediments reduced $\mathrm{Cr}(\mathrm{VI})$ for $\sim 30$ pore volumes (K. Telfeyan, A. Migdisov, P. Reimus)

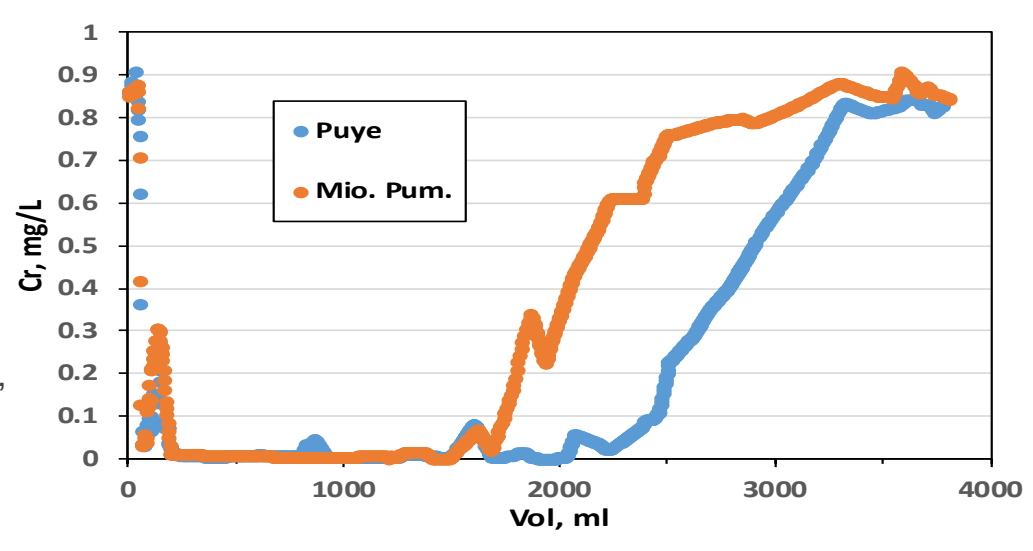




\section{Field Capabilities-Engineered Solutions}

\section{- Tracer Testing}

- Multi cross-hole tracer tests at TA-16

- Down gradient monitoring network

- Legacy Management Projects on transport of $U$ at Grand Junction, CO

- Grand Junction Field Tests: injection and tracer tests to characterize shallow groundwater and surface water interactions.

- U liberated during tests, suggesting $U$ mobilization and ongoing uranium sources

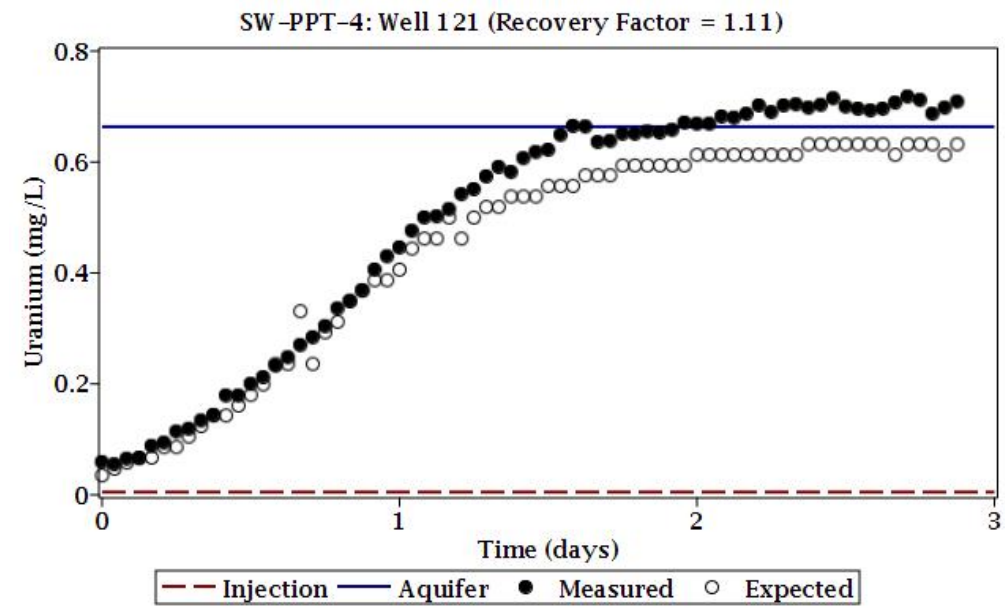

Single-well push-pull test

C. Paradis, P. Reimus, R. Johnson

\section{- Amendment Testing:}

- Establish long-lasting in-situ permeable biogeochemical barriers using sodium dithionite and molasses

- Dithionite treatment appears to be viable

- EM considering large-scale dithionite deployment

- Molasses treatment reduces Cr(VI)

Pilot study demonstrating reduction and precipitation of $\mathrm{Cr}(\mathrm{VI})$ (P. Reimus)

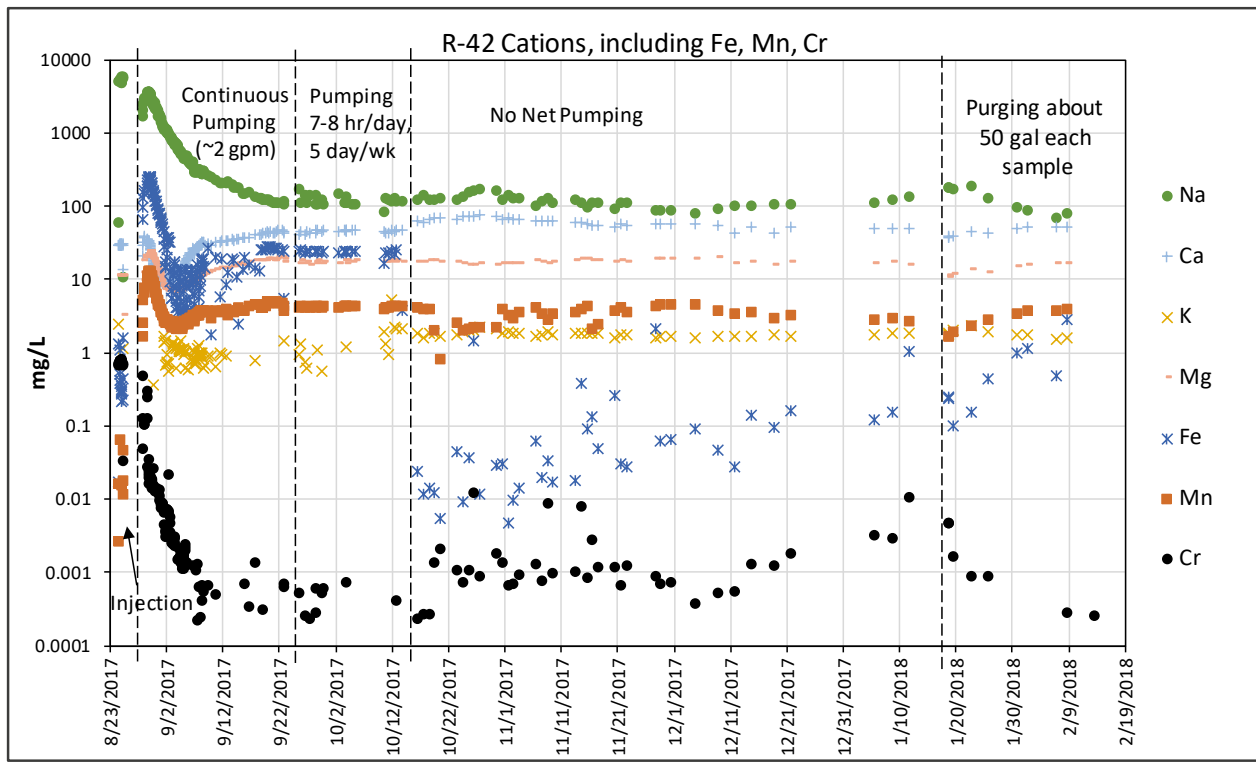

- Land Fill Covers:

- Multiple cover designs with 30+ year history - Available to examine long-term performance 


\section{Field Capabilities-Unmanned Aircraft System (UAS)}

- Monitoring environmental changes

- Datasets characterize the relationships between topography and hydrology, biogeochemistry, geomorphology

- Alaska and Nevada Test Site

- LIDAR

- Point cloud density: 740 pts $/ \mathrm{m}^{2}$

- DEM resolution: $2 \mathrm{~cm}$

- PHOTOGRAMMETRY

- Point cloud density: 4,770 pts/m²

- DEM resolution: $1.7 \mathrm{~cm}$

- In progress: methane sensor for in-situ methane measurements

Aircraft: Vulcan Raven Heavy-Lift Co-axial Octocopter
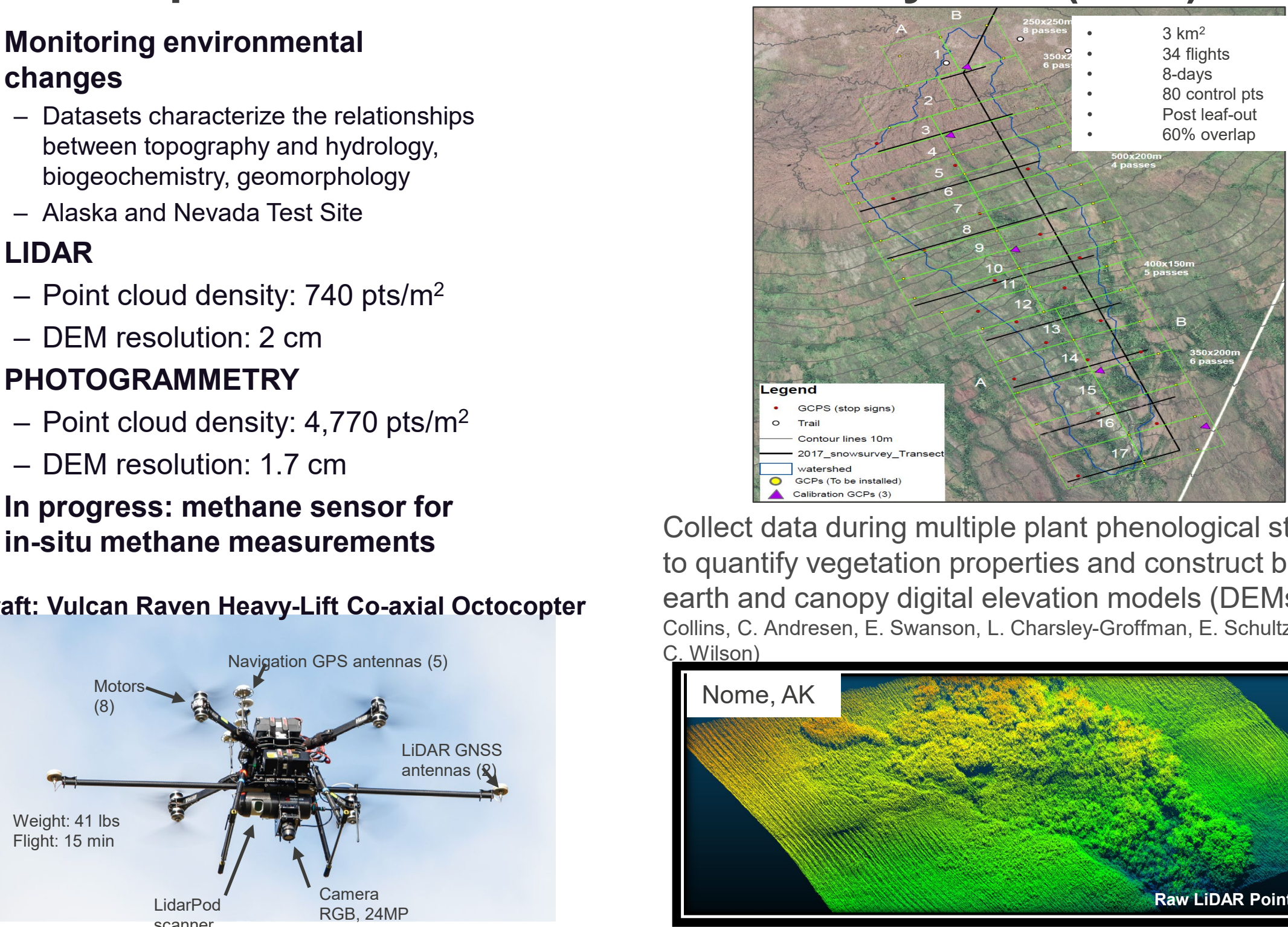

Collect data during multiple plant phenological stages to quantify vegetation properties and construct bareearth and canopy digital elevation models (DEMs) (A. Collins, C. Andresen, E. Swanson, L. Charsley-Groffman, E. Schultz-Fellenz, C. Wilson)

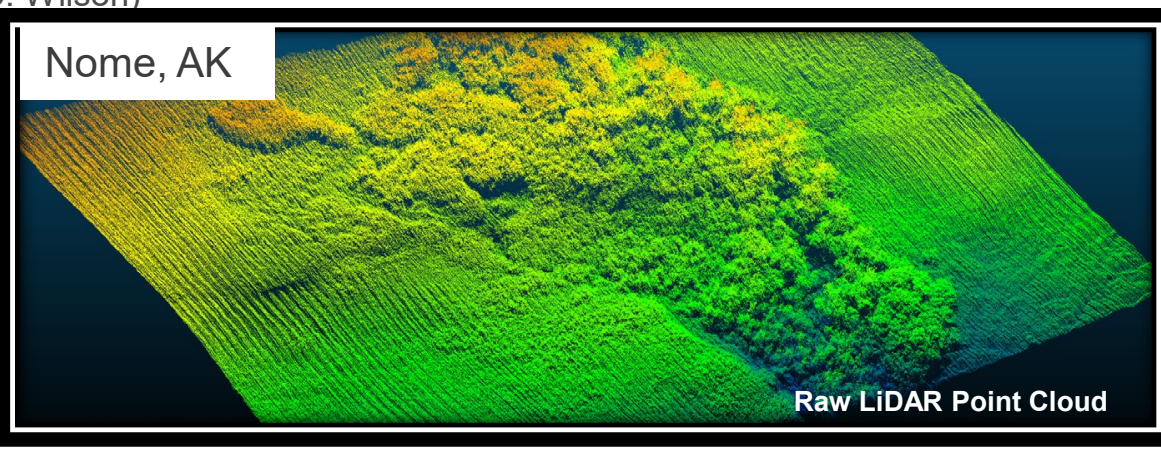




\section{Selected References}

- Dangelmayr, et al., 2018. Uncertainty and variability in laboratory derived sorption parameters of sediments from a uranium in situ recover site. Journal of Contaminant Hydrology, 213: 28-39.

- Heerspink et al., 2017. Fate and transport of hexahydro-1,3,5-trinitro-1,3,5-triazine (RDX) and its degradation products in sedimentary and volcanic rocks, Los Alamos, NM. Chemosphere 182: 276-283.

- Heikoop et al., 2014. Isotopic evidence for reduction of anthropogenic hexavalent chromium in Los Alamos National Laboratory groundwater. Chemical Geology, 373: 1-9.

- Koger et al., 2018. Chemostatic behavior of major ions and contaminants in a semiarid spring and stream system near Los Alamos NM, USA. Hydrologic Processes, 32(11): 1709-1716.

- Telfeyan et al., 2019. Long-term stability of dithionite in alkaline anaerobic aqueous solution. Applied Geochemistry, 101: 160-169.

- Wang et al., 2016. Biostimulation and microbial community profiling reveal insights on RDX transformation in groundwater. MicrobiologyOpen, 6(2), e00423.

- Compendium of technical reports related to the deep groundwater investigation for the RDX project at Los Alamos National Laboratory (LA-UR-18-21326)

- Compendium of technical reports to the chromium project at Los Alamos National Laboratory (LA-UR-18-21450) 


\section{Additional Slides}




\section{Two Pilot Tests of $\mathrm{Cr}(\mathrm{VI})$ Remediation in Mortandad Canyon}

- Chemical Reductant: Sodium Dithionite - 10,000 gallons injected Aug. 24-25, 2017 - 3 days in aquifer, then pumped back

- About 77,000 gallons pumped, then passive sampling since mid Oct. 2017
- Biostimulant: Molasses

- 30,000 gallons injected Sept. 9, 2017

- Passive sampling since then, except for 1000 gallons pumped Nov. 20, 2017

\section{sampling since mid Oct. 2017}

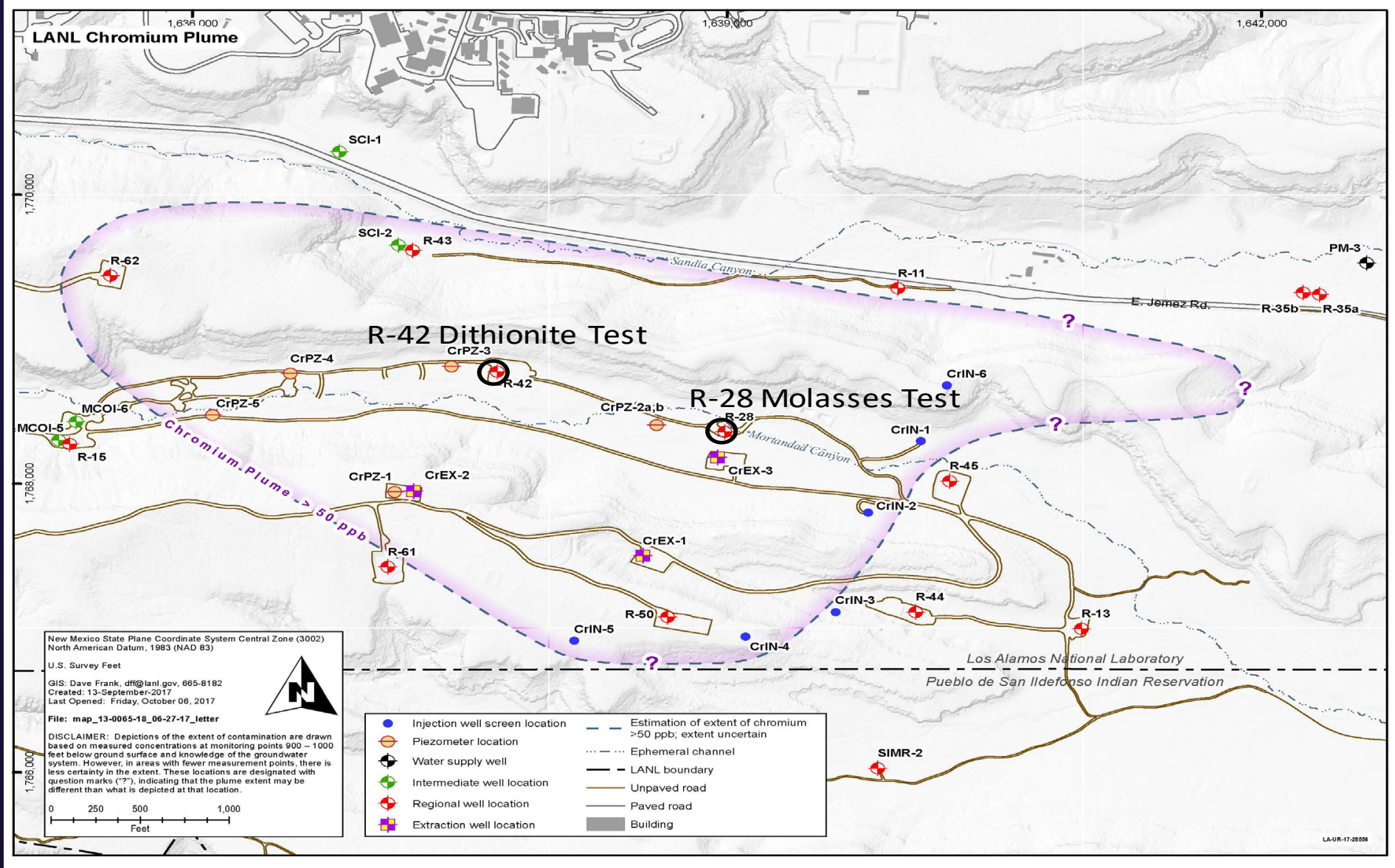




\section{Smith-Ranch Highland, WY}

- Sodium dithionite treatment for groundwater restoration of U-contaminated mining site at Smith-Ranch Highland Site in WY.

- Effective treatment except for sediments with high organic matter

- Push-pull Field Tests

$-6,000$ gallons $0.05 \mathrm{M}$ dithionite injected (30 $\mathrm{min} / 1000 \mathrm{gal}$ ), reacted for 60 hours, and pumped back (4.7 gpm) for 2 months

- $U$ isotope analysis indicates reduction occurred
$\mathrm{U}$ and $\mathrm{Cl}$ breakthrough curves for sediment treated with sodium dithionite (R. Harris, P. Reimus, M. Dangelmayr)
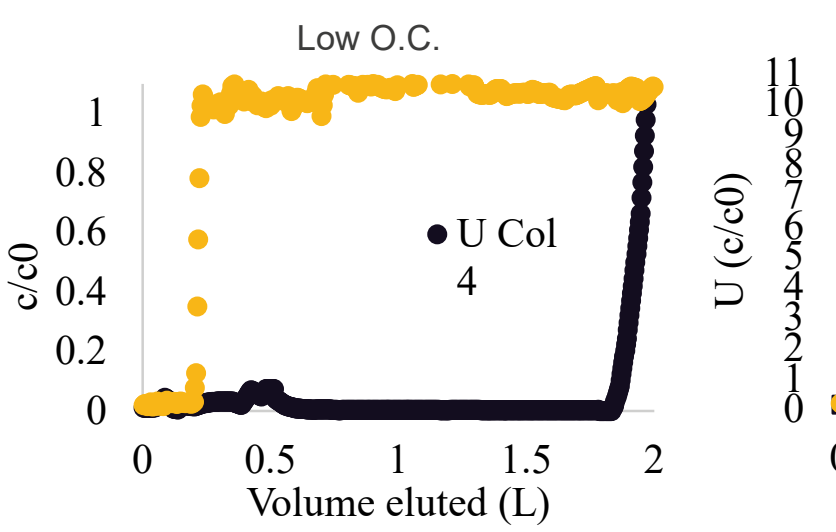

High O.C.

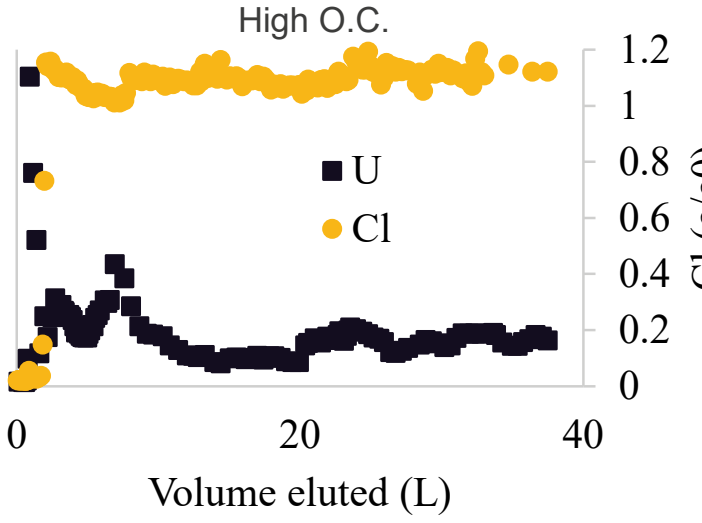

$U$ reduction and decreased concentrations after treatment with dithionite (R. Harris, P. Reimus)

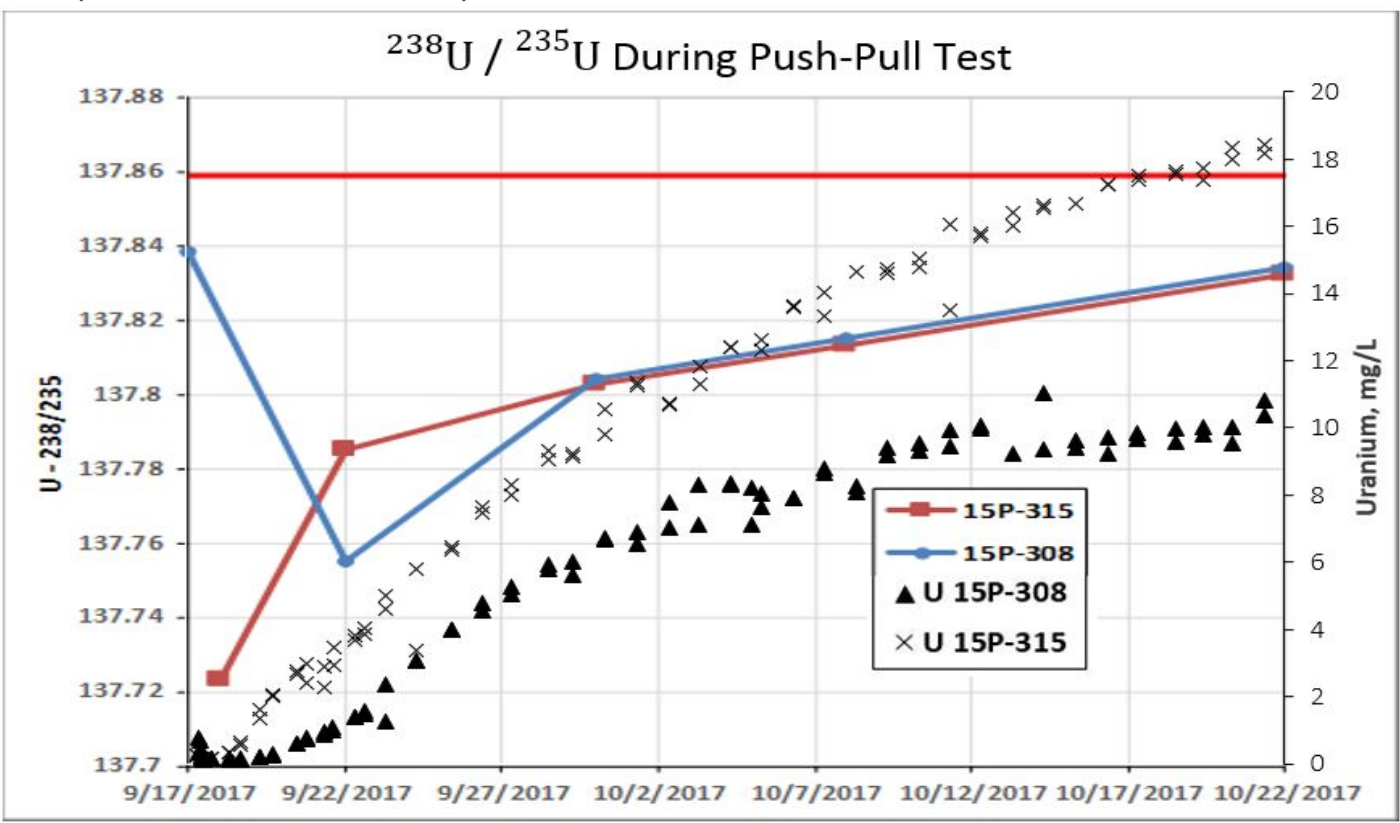




\section{Sandia Wetland}

\section{- Legacy $\mathrm{Cr}$ and PCBs}

- The reducing and organic sediment of the wetland:

Deduced the $\mathrm{Cr}(\mathrm{VI})$ to immobile $\mathrm{Cr}(\mathrm{III})$

$>$ Adsorbed PCBs to organics in sediment

- $\sim 15,000 \mathrm{~kg}$ inventory of $\mathrm{Cr}(\mathrm{III})$ in the wetland sediment

- D. Musa, J. Heikoop evaluated geomorphic stability, vegetative health, water chemistry, water level
$\mathrm{Cr}$ at or below detection levels (D. Musa, J. Heikoop)
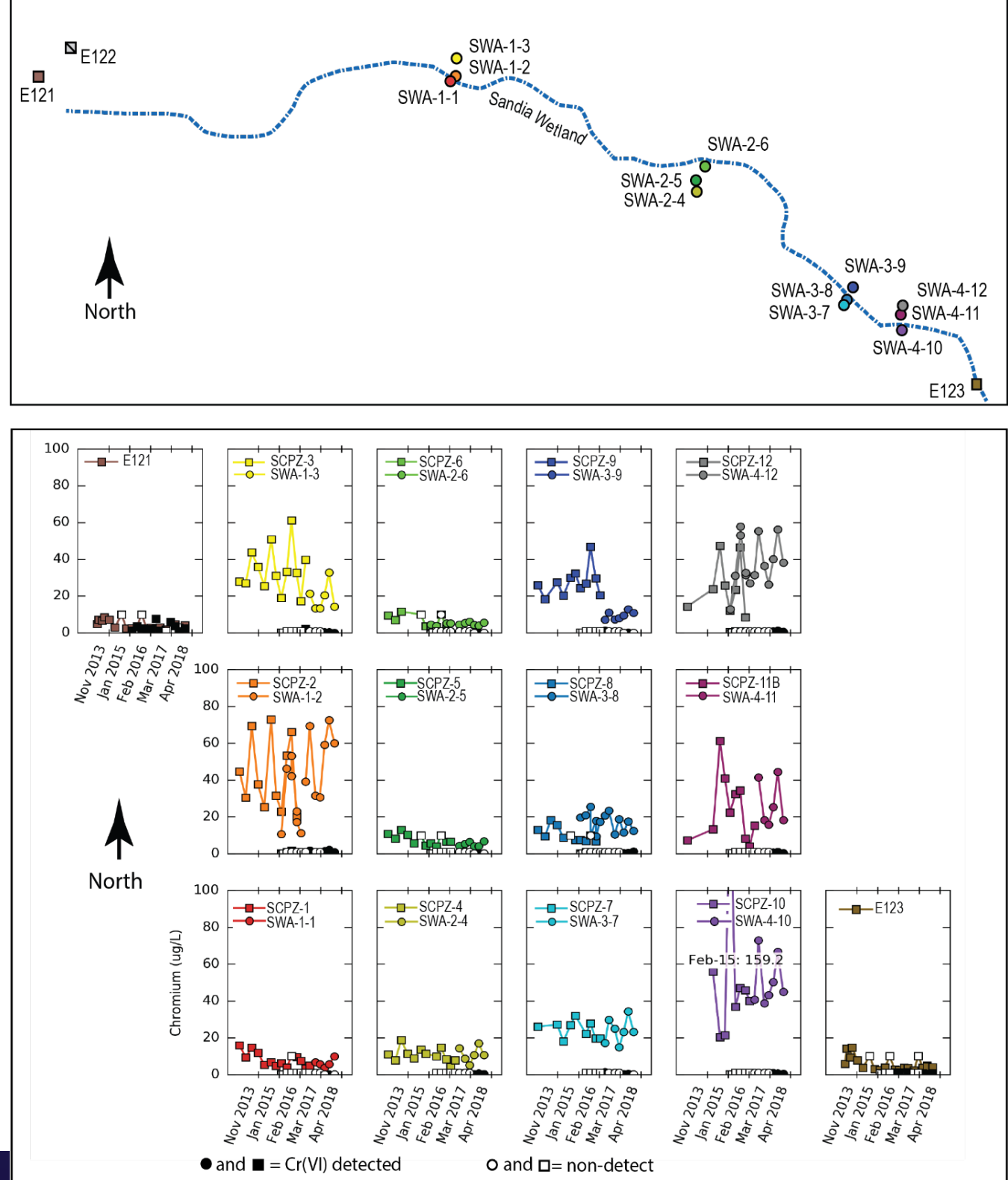


\section{Concentration-discharge behavior of high explosives}

- TA-16 contaminated with high explosives

Chemostatic behavior of solutes (Koger et al., 2018)

- Study on the concentrationdischarge relationship of contaminants (RDX, BA) in springs.

- RDX and Ba displayed chemostatic behavior in the surface water and springs. The contaminated soil was removed from the source area, but the contamination persists in springs that drain the area.

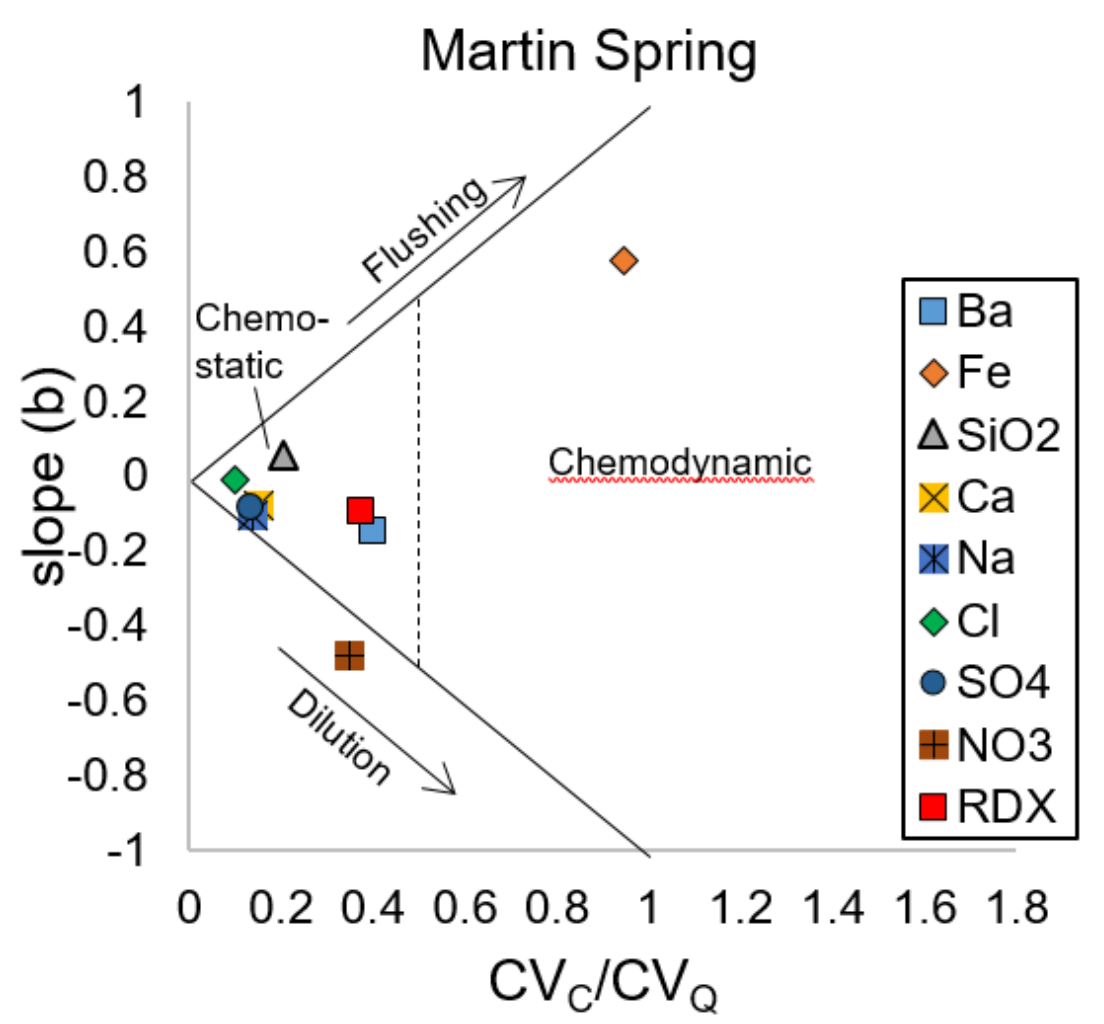

